\title{
Development of a Conceptual Framework Depicting a Child's Total (Built, Natural, Social) Environment in Order to Optimize Health and Well-Being
}

\author{
Nicolle S. Tulve ${ }^{1 *}$, Jazmin D.C. Ruiz ${ }^{2}$, Kim Lichtveld², Sally P. Darney ${ }^{3}$, James J. Quackenboss ${ }^{4}$
}

${ }^{1}$ U.S. Environmental Protection Agency, Office of Research and Development, National Exposure Research Laboratory, Research Triangle Park, NC, USA

${ }^{2}$ ORISE Post-Doctoral Participant, U.S. Environmental Protection Agency, Office of Research and Development, National Exposure Research Laboratory, Research Triangle Park, NC, USA

${ }^{3}$ U.S. Environmental Protection Agency, Office of Research and Development, National Health and Environmental Effects Research Laboratory, Research Triangle Park, NC, USA

${ }^{4}$ U.S. Environmental Protection Agency, Office of Research and Development, National Exposure Research Laboratory, Las Vegas, NV, USA

*Corresponding author: Dr. Nicolle S. Tulve, U.S. EPA, 109 T.W. Alexander Dr., MD-E-205-04, Research Triangle Park, NC, 27711, Tel: (919)541-1077; Fax (919)541-0905; E-mail: tulve.nicolle@epa.gov

\begin{abstract}
The complexity of the components and their interactions that characterize children's health and well-being are not adequately captured by current public health paradigms. Children are exposed to combinations of chemical and non-chemical stressors from their built, natural, and social environments at each lifestage throughout their lifecourse. Children's inherent characteristics (e.g., sex, genetics and epigenetic factors) and their activities and behaviors also influence their exposures to stressors from these environments. We describe a conceptual framework that illustrates the interrelationships between inherent characteristics, activities and behaviors, and stressors from the built, natural and social environments in influencing children's health and well-being as they progress through various stages of development. We demonstrate the use of this framework for two major public health concerns: childhood obesity and diminished general cognitive ability. Systematic reviews of the literature found a limited number of studies that evaluated both chemical and non-chemical stressors. For example, neighborhood-level socioeconomic factors and chlorpyrifos exposure were shown to interact to impact cognitive function and maternal self-esteem was found to modify vulnerability to prenatal lead. By better understanding these complex interactions, decision makers can make informed choices for child-specific environments that optimize health and well-being within the home and community.
\end{abstract}

Received date: September 16, 2016 Accepted date: October 8, 2016 Published date: October 14, 2016

Citation: Tulve, N.S., et al. Development of a Conceptual Framework Depicting a Child's Total (Built, Natural, Social) Environment in Order to Optimize Health and Well-Being. (2016) J Environ Health Sci 2(2): 1- 8 .

DOI: $10.15436 / 2378-6841.16 .1121$

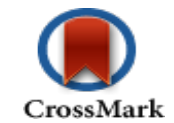

Keywords: Children; Holistic; Framework; Chemical; Non-chemical; Stressors; Built; Natural; Social environments 


\section{Introduction}

The complexity of the components that contribute to children's health and well-being is not adequately captured by current public health paradigms. Children are exposed to a wide variety of chemical and non-chemical stressors from their built, natural, and social environments, and these stressors change over time as children develop and occupy new environments. Children's physiological functions, surface-to-volume ratio, developmental stage, inherent characteristics (e.g., sex, age and illness status) and age-dependent activities and behaviors individually and collectively influence their exposures to chemical and non-chemical stressors from these environments. Children, as compared to adults, may be more vulnerable to the interrelationships between chemical and non-chemical stressors from their built, natural, and social environments, at each lifestage ${ }^{[1,2}$ and across the lifecourse, impacting their lifelong health and well-being ${ }^{[3-5]}$. We need to understand and consider the complexity of the components that contribute to children's health and well-being and their interrelationships in order to provide children with environments that are both protective and health promoting.

In general, conceptual frameworks published in the peer reviewed literature have illustrated relationships between a single stressor or group of related stressors and an outcome of interest. Examples include a conceptual model linking parks with physical activity and public health ${ }^{[6]}$, a conceptual framework for environmental features related to physical activity ${ }^{[7]}$, and a framework studying the mediators and moderators of childhood obesity ${ }^{[8]}$. While these frameworks may be useful, individually they do not adequately describe the overlaps and interdependencies among components in a child's total environment, which together form the real-world exposures to combinations of chemical and non-chemical stressors that may influence health and well-being.

Recent publications have proposed more complex conceptual frameworks with a specific purpose in mind, such as consideration of combination of stressors, multiple aspects of the total environment, added complexity, and/or more inclusivity ${ }^{[4,9-23]}$. For example, Segal, D. et al., 2015. ${ }^{[24]}$ described a conceptual framework to evaluate the interactions of exposure to lead and psychosocial stress (one chemical and non-chemical stressor) in informing risk assessment. Juarez, P.D. et al., 2014. ${ }^{[4]}$ published a concept paper on the public health exposome, describing it as a universal exposure tracking framework for integrating complex relationships between exogenous and endogenous exposures across the lifecourse. The authors describe this social-ecological framework as a mechanism to eliminate health disparities at the population level by incorporating data from the natural, built, social, and policy environments ${ }^{[4]}$. While these frameworks expand single relationships to consider multiple relationships, they still lack the ability to describe the interrelationships between chemical and non-chemical stressors, inherent characteristics, activities and behaviors, and children's health and well-being ${ }^{[15,17,25]}$.

To understand the interrelationships between chemical and non-chemical stressors from the built, natural, and social environments, we developed a multifactorial conceptual framework. This framework shows how aspects of the built, natural, and social environments need to be considered together, in com- bination with activities and behaviors and inherent characteristics, to holistically characterize children's health and well-being. It includes the many factors that impact children's health at each stage of development, and illustrates how these factors interact, in order to help attribute, reduce and eliminate risks specific to environmental exposures. The objectives of this manuscript are to 1) present the framework as a holistic approach to the complex interactions that determine the health and well-being of a child across the lifecourse, and 2) provide examples of how this framework can be used when considering children's health and well-being.

\section{Methods}

Through a survey of the literature, we identified existing conceptual frameworks that have been designed to support research on various aspects of children's environmental health and assessed their components, interrelationships between components, and links to children's health and well-being. We used these existing frameworks and the current state of knowledge of children's health, supported with evidence from the peer reviewed literature, to develop a more holistic, multifactorial conceptual framework. We designed this framework to show how all relevant aspects of the built, natural, and social environments need to be considered together, in combination with activities and behaviors and inherent characteristics, to holistically characterize environmental determinants of children's health and well-being and inform decision-making.

\section{Results}

\section{Conceptual Framework}

A child's health and well-being are the product of his/ her inherent factors (e.g., race, sex and genetics), activities and behaviors, and total environment (Figure 1). The total environment is comprised of the built, natural, and social environments where a child lives, learns, and plays (i.e., home, school, daycare and community). Chemical and non-chemical stressors come from the total environment. As depicted, this framework includes effects and relationships across all scales, starting from the smallest or micro scale (e.g., cellular and molecular alterations) to the largest scale (e.g., the community, which varies by its geographic, physical and social composition). The consideration of factors across scales reflects the importance of policies and decisions made at the national, state, and local levels as well as social norms and decisions made within the home. The overlapping circles and two-way arrows emphasize the bi-directionality of relationships, while the arching arrow represents the dynamics of the system wherein a child's health and well-being are constantly evolving over time as they grow and mature across the lifecourse. Finally, the size of the circles represents the cumulative, additive, multiplicative, or synergistic effects in response to exposure. Each component of the framework is described in more detail in the following sections. 


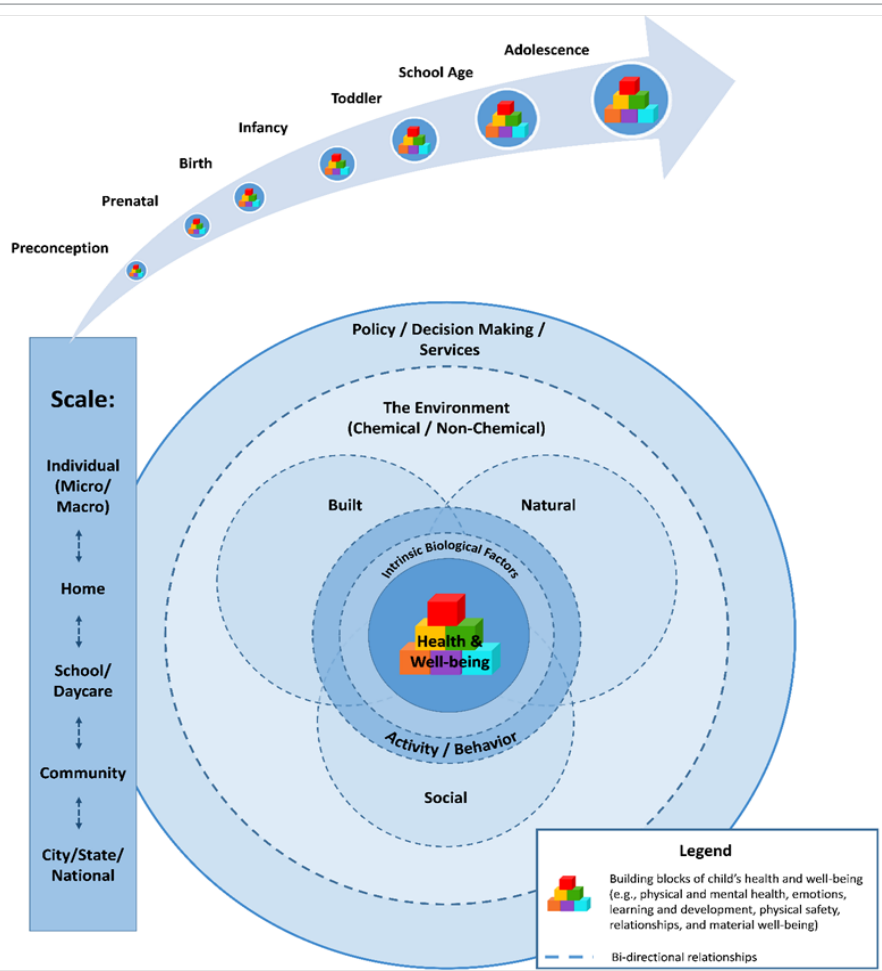

Figure 1: Conceptual framework depicting children's health and well-being. See text for details. Not to scale.

\section{Components of the Framework}

Child Health and Well-Being: The health and well-being of a child is the central part of Figure 1 and the intended goal of this framework is to incorporate the totality of interrelationships among the built, natural, and social environments, inherent characteristics, and activities and behaviors in influencing children's health and well-being. This framework shows that multiple factors are interrelated when considering child-specific health and well-being outcomes and that these outcomes may also be interrelated. For example, chronic sickness or illnesses (e.g.,

asthma) can affect not only physical health but also lead to decreased physical mobility and the desire to explore, which in turn may limit cognitive and social development. Thus, health in early life influences a child's future health and well-being, lifelong success, and eventual contributions to society. A holistic view of children's health and well-being considers all factors of development, including but not limited to protecting and nurturing physical and mental health, developing meaningful social relationships, and emotional and physical well-being ${ }^{[25-29]}$. Building blocks, symbolic of children's toys, are displayed in increasing sizes representing the progress of healthy development and indicate how disruption at a stage can deter a child's ability to achieve his/her full potential. We emphasize that the building blocks are important even before conception, with each stage of development forming the basis for successive stages.

Intrinsic Biological Factors: Biological determinants of health include age, lifestage, sex, genetic predisposition, genetic polymorphisms, prior immune reactions, pre-existing health conditions, disease state, or prior damage to cells or systems ${ }^{[20]}$. Intrinsic factors have historically been envisioned to be relatively fixed in nature. However, we are learning that a child's microbiome, established during the first few years of life and an important determinant of subsequent health, is malleable by the environment, infectious disease, and diet. The microbiome can also modulate the nature and effect of an environmental exposure, for example, by metabolizing a contaminant or by changing the body's immune response to $\mathrm{it}^{\left[{ }^{30-32]}\right.}$. Likewise, a child's epigenome, established in very early prenatal development, is modifiable by subsequent environmental stressors, and thereby, provides mechanisms for environmental resilience throughout life ${ }^{[33]}$. Although intrinsic factors are generally less readily changed than environmental factors, they need to be considered in order to make informed decisions related to creating healthy environments for children.

Activity/Behavior: Children's activities and behaviors, especially the way children interact with their environment, may have an effect on their exposures ${ }^{[3,34]}$. Children's activities are highly intermittent and vary in intensity between quiet and active play depending on the time of day and setting ${ }^{[35,36]}$. Children are more likely than adults to engage in activities that put them into contact with potential stressors found in their everyday environment and these activities change as a function of their developing motor capacities. As children gain mobility and extend the boundaries of their interactions, their activities change from crawling on the floor to walking and running, and subsequently their exposures to chemical and non-chemical stressors begin to vary (e.g., other potentially contaminated surfaces in the home, new social influences, outdoor pollutants, recreational facilities and green space $)^{[3,7,37]}$. With this extension of boundaries, children's exposures to non-chemical stressors begin to vary as a function of influences at home, from peers or modeling/ mimicking what is seen in the community ${ }^{[38]}$. As children move through their lifecourse, they may also participate in risky behaviors associated with dietary habits, smoking, alcohol use and/ or emotional behaviors as a result of social interactions, possibly resulting in adverse health outcomes ${ }^{[39]}$.

\section{The Environment: Chemical and Non-Chemical Stressors:}

The total environment consists of chemical and non-chemical stressors from the built, natural, and social environments where a child lives, learns, and plays (i.e., home, school, daycare and community $)^{[22]}$. We define stressors as any physical, chemical, social, or biological entity that can induce a change (either positive, negative or neutral) in a child's health and well-being (either now or into the future). Chemical stressors are defined as exogenous environmental compounds. Chemical stressors change or damage living organisms or ecosystems and are released into the environment by waste, emissions, pesticide use or uses of formulated compounds like pharmaceuticals ${ }^{[21,40,41]}$. Children are exposed to chemical stressors from the foods they eat, water they drink, air they breathe, and surfaces they touch (e.g., chemical residues on surfaces or in dust and soil) and their lifestage-specific diets and activities and behaviors influence the nature and extent of their exposures. Non-chemical stressors are factors found in the built, natural and social environments including physical factors such as noise, temperature, and humidity and psychosocial factors (e.g., poor diet, smoking, and illicit drug use) (see example references such as (Miranda, M.L., et al., 2012; Gray, S.C., et al., 2014; Strominger, J., et al., 2016; Shmool, J.L.C., et al., 2015; Clougherty, J.E., et al., 2007) ${ }^{[42-46]}$ ). Exposures to both chemical and physical stressors are deter- 
mined, in part, by a child's proximity to hazardous waste sites, power plants, and other sources of pollution, and this, in turn, is influenced by social considerations such as family income and standard of living. Social factors in a child's community, such as community traditions and beliefs and access to health care, to name a few, can modulate the impact of the environment on a child $^{[20,40,43,45-47]}$. Additionally, evidence suggests that non-chemical stressors can act as modifiers of a child's biological response to chemical exposures, altering his/her susceptibility to chemical agents and the severity of resultant health effects ${ }^{[46,48]}$. Finally, cumulative exposures to chemical and non-chemical stressors in the home and community are often related in time and space. For example, communities can be exposed to both point source emissions from highways and lack of healthy food options ${ }^{[9]}$.

Built Environment: The built environment refers to the manmade surroundings that provide the setting for human activity, including but not limited to, land use (e.g., open space, green space, buildings and connectivity), transportation systems (both motorized and non-motorized), buildings, infrastructure (e.g., water supply and energy networks), and waste and materials management ${ }^{[42,44,49-52]}$. The built environment serves as a source of stressors that influence health and well-being due to access and availability (or lack thereof) of water and energy supplies, food quality and quantity, green space, sidewalks/trails, parks and recreational services, building quality, violence/crime, and health care, to name a few. The built environment also influences exposures to environmental hazards, such as chemicals. All of these stressors combine to influence how children interact with their environment, impacting their overall health and well-being ${ }^{[42,53,54]}$. For example, if a child does not live within walking distance of a park/playground and is not able to get to the park/ playground safely, then this child may not engage in active play, and suffer long-term health consequences of a sedentary lifestyle.

Natural Environment: The natural environment encompasses all living and non-living things naturally occurring on Earth, including water, air, mineral, climate, natural disasters, previously living organisms, forests, fields, lakes, mountains, and undeveloped natural vegetation that humans interact with on a daily basis ${ }^{[9,55]}$. Studies have shown that activity in the natural environment can promote health and well-being by improving mental and social health, longevity, ecological knowledge, activity, and feelings of community safety ${ }^{[17,25,55-59]}$. Studies examining biological responses (e.g., blood pressure, heart rate and cortisol levels) have also shown that interactions with the natural environment reduce stress levels and improve overall well-being $^{[55,57,58]}$. The beneficial effects associated with the natural environment are not only a result of direct human interactions, but interactions with other domains of the environment. For example, green space in urban areas can improve air quality, regulate climate conditions, reduce noise pollution from traffic, provide a sense of community and kinship, and increase a neighborhood's economic value ${ }^{[25,60-62]}$. The natural environment also includes exposure to naturally-occurring chemical stressors such as arsenic in groundwater ${ }^{[63-67]}$ and ionizing radiation from bedrock ${ }^{[68]}$.

Social Environment: The social environment includes not only social interactions but factors such as the economy, community, home, school/daycare, demographics, safety, and welfare, to name a few ${ }^{[4,69]}$. For children, social influences on their physiological health and psychological well-being are influenced by their family, peer relationships, school environment, and neighborhood interactions and may be mediated by physiological responses associated with stress. Communication with parents and other family members shapes a child's behavior in their community which, in turn, influences their health and well-being. Strong family support assists children in dealing with stressful situations in positive ways, whereas, weak family environments may lead to negative or risky behaviors ${ }^{[70]}$. When compared to adults, children may experience different stressors in the home that may influence a child's ability to respond and react to stress. Peer relationships help form identity and develop social skills and self-esteem, which are invaluable for school-aged children throughout their lifecourse. Children spend the majority of their day in school/daycare where they learn and play. The school/ daycare is influenced by the type of community, location, and available resources. School/daycare provides sources of both positive and negative stressors for children, including positive learning environments for education and the development of social skills, recreation, and active outdoor play. Recent research has shown, for example, that school lighting, temperature, and the absence of noise contribute positively to learning (https:// www.epa.gov/schools). Likewise, potential negative stressors associated with insufficient funding, poor social interactions (e.g., bullying) and poor infrastructure (e.g., chemical exposures, mold and crime $)^{[39,71]}$ can be detrimental to learning, as well as biological health. Positive neighborhood interactions provide a sense of security and safety that promotes healthy behaviors. Social relationships in the community can be influenced by societal networks, race/ethnicity, socioeconomic level, and community engagement. Socioeconomic stressors from parental education levels, income, number of people in the home, dietary provisions, quality and accessibility of food sources, housing, and parental or community distress can all negatively influence a child's behavior and sense of self-worth as they live in their communities. Studies have shown that societies with perceived levels of higher well-being are those that are more economically developed, have effective governments with low levels of corruption and high levels of trust, and can meet citizens' basic needs ${ }^{[53]}$.

Policy, Decision Making, Services: The nature of a child's total environment depends on the actions of many types of decision makers, including parents, researchers, public officials, and others (Figure 1). Understanding and taking into consideration the factors and domains that comprise a child's environment can help decision makers redevelop, repurpose, or create healthy environments that foster healthy children. Children's health in the United States is affected by laws, rules, and regulations developed at the national, state, and local levels ${ }^{[72]}$. Policies set by the government may not always be obvious when examining children's health, but can include policies for access to food stamps, nutrition programs (including free lunch programs), social services, youth recreation programs, and other health and human development programs, as well as quality education ${ }^{[70]}$. Local governments and municipalities have authorities that address activities and opportunities that federal and state rules do not cover. For example, child-relevant decisions could have negative impacts on children's health and performance related 
to poorly sited schools and inappropriate building materials and operation practices ${ }^{[71]}$. Municipalities also have unique authority to make decisions regarding local financial and environmental resources to improve neighborhood quality which may, in turn, impact children's health and well-being ${ }^{[70]}$. For example, decisions on providing solid waste collection and disposal, maintaining and diversifying transportation options, developing building codes and zoning for land use planning, and implementing public-private partnerships to meet infrastructure needs all impact the health and well-being of the residents of the community ${ }^{[73]}$. In addition, the state of child health and well-being and the environment can stimulate intervention research and policy development through evidence-based research, health or environmental impact assessments, economic incentives, and identification of $\operatorname{disparities}^{[9,12,74]}$

The Scale: Our framework describes a system that considers both proximal and distal effects and relationships across spatial scale (i.e., policies made at the national level affect the local level and decisions made at the individual level affect the home environment and vice versa) in impacting health and well-being. It is important to recognize the co-occurring and unique exposures that children experience as a result of decisions made for them at each level of scale ${ }^{[36,70]}$. Our framework considers that stressors may affect a child at specific scales and across all scales.

Arrow: The arrow emphasizes four points of lifecourse theory: cumulative exposure, transgenerational impacts, timing of exposures, and trajectory of growth and development (Figure 1). There is a growing body of literature suggesting that these concepts should be evaluated together ${ }^{[12,21,39,75-77]}$. However, translating this theory into research and practice is challenging. The arrow points to the underlying causes of persistent and multiple inequalities within a child's proximal and distal environments over time. The cumulative impact of multiple stressors and protective factors over subsequent lifestages during the lifecourse may have a greater impact on health and well-being than any individual stressor or protective factor on a healthy or compromised trajectory ${ }^{[36]}$. The arrow emphasizes the need to explore exposure across a sequence of lifestages with the recognition that there are distinct time frames in life that are characterized by unique behavioral or physiological characteristics (e.g., pre-conception, prenatal, infancy, toddlerhood, adolescence, adulthood and aging). Each lifestage may be differentiated by particular vulnerabilities to exposures (e.g., pathways, source, settings and target organs). The effect of a single stressor or mixture of stressors (whether chemical, non-chemical, or mixture of chemical and non-chemical) does not dictate current or ultimate health and well-being; rather, the trajectory of this outcome is constantly evolving over time which can be attributed to an integrated continuum of exposures, experiences, responses, and interactions specific to each child, resulting in a unique health and well-being outcome for each child. Childhood health and well-being is a product of the continuous interactions between genes, epigenetic factors, and other inherent factors, individual choices and behaviors, and a child's total environment.

\section{Discussion}

We describe a conceptual framework that considers the complex interrelationships among inherent characteristics, activities and behaviors, and stressors from the built, natural, and social environments as they influence children's health and well-being throughout their lifecourse (Figure 1). This systems-based thinking provides an integrated view of children's health and well-being as well as insights into actions that decision makers can take to improve their local environments and their health and well-being, whether at the individual, home, or community level[ ${ }^{[73]}$.

Our conceptual framework builds upon and extends available frameworks and tools by incorporating inherent characteristics, activities and behaviors, and stressors from the built, natural, and social environments in describing children's health and well-being. This framework emphasizes the complex interrelationships within a child's environment and the cumulative effects at each lifestage and throughout the lifecourse. It incorporates both chemical stressors, pertinent to regulatory agencies such as the U.S. EPA, U.S. FDA, and USDA, with non-chemical stressors, suggesting that there are interactions across all spatial scales and within and between environments. While specific to children's health and well-being, this framework is also relevant to other lifestages and adaptable as emerging research areas become better understood (e.g., microbiome research).

Other well-known models have more specific purposes. For example, the DPSIR (Driving Force-Pressure-StatusImpact - Response) model, designed to examine environmental stressors and responses, has been applied to health; however, this has been done in the context of specific stressor/outcome relationships such as asthma, as opposed to the total environment across the lifecourse ${ }^{[78]}$. On the other hand, models of children's health that incorporate the lifecourse have focused primarily on a biomedical health agenda, as opposed to an environmental health agenda ${ }^{[79]}$.

The World Health Organization has proposed more holistic models that incorporate environmental components. DPSEEA (Driving Force-Pressure-State-Exposure-Effect-Action) was developed to support the development of environmental health indicators by using a process that incorporates driving forces $\rightarrow$ pressures $\rightarrow$ environmental states $\rightarrow$ exposures $\rightarrow$ health conditions or effects ${ }^{[13,22]}$. It allows for links between exposure and health effects with several points of entry into the cause and effect chain and takes into account non-chemical stressors with ease and flexibility by assessing the problem using an interlinking approach. The MEME (Multiple Exposures-Multiple Effects) framework focuses primarily on children and their environmental health indicators. This framework focuses on the notion that children's health can be affected by multiple effects and various exposures and tries to link individual exposures and different health outcomes, but has difficulty separating exposure and causality. The IEHIA (Integrated Environmental Health Impact Assessment) model recognizes the approach of these frameworks and examines health-related problems from the impact of policies related to environment and health while taking into account all the complexities of the real world in a non-linear fashion. The IEHIA framework combines qualitative and quantitative approaches that require a strong interdisciplinary approach with varying levels of interest and expertise $^{[13]}$.

The PHE (public health exposome) conceptual model integrates information about endogenous and exogenous source-exposure-disease relationships with mediating and mod- 
erating factors at both the individual and population health levels to understand the underlying causal mechanisms through which environmental exposures act. It addresses chemical stressors and does not consider non-chemical stressors or activities and behaviors. The PHE conceptual model can also be used to support data organization as well as hypothesis generation ${ }^{[4]}$. Each of these frameworks has elements that are applicable to our conceptual framework. However, our conceptual framework incorporates all of these elements into one framework that integrates inherent characteristics, activities and behaviors, chemical and non-chemical stressors from the built, natural, and social environments, and children's health and well-being.

Our framework can be used to identify gaps in knowledge that limit the ability to make fully informed, systems-based decisions and identify potential unintended consequences. Researchers and decision makers adapting this framework can provide and use information and data for available tools (e.g., CFERST (Community-Focused Exposure and Risk Screening Tool, and HIAs (Health Impact Assessments)) which can help communities identify and prioritize risk factors associated with childhood disparities or improve child-specific environments in their community (https://www.epa.gov/healthresearch/community-focused-exposure-and-risk-screening-tool-c-ferst; https:// www.epa.gov/healthresearch/health-impact-assessments). The potential implication of alternative decisions on children's health and well-being could also be readily identified using this framework.

We used this conceptual framework to explore the interrelationships between chemical and non-chemical stressors and selected child-specific health outcomes, namely children's general cognitive ability and childhood obesity. Ruiz, J.D.C., et al., 2016 ${ }^{[80]}$ completed a systematic scoping review of the stressors identified with general cognitive ability for young children. This systematic scoping review collated evidence associated with children's cognitive health, including inherent factors as well as chemical and non-chemical stressors from the built, natural, and social environment. In a similar fashion, Lichtveld, K., et al., 2016 ${ }^{[40]}$ conducted a systematic scoping review of the stressors associated with childhood obesity. Both reviews show the importance of using a conceptual framework to identify and organize the myriad chemical and non-chemical stressors that a child may be exposed to and how these exposures affect health and well-being, as well as the importance of prioritizing stressors for future research.

As with any conceptual framework, there are potential limitations. One potential limitation is a lack of data and information that is sufficient to address every aspect of a child's environment (as shown in Figure 1) in order to understand the interrelationships impacting a child's health and well-being (e.g., asthma, and obesity). We clearly know more about some factors than others; hence the need to prioritize stressors for future research. Another potential limitation in applying the framework to make decisions is the need for a multidisciplinary (e.g., microbiome research, environmental science, social sciences, policy makers, and risk assessors) collaborative approach when addressing children's health and well-being. Designing stud(y/ ies) that incorporate all aspects of the holistic child will be expensive, necessitating unique thinking on how to generate all data and information for multiple lifestages throughout the life- course. Therefore, new data collection approaches and computational modeling efforts will be useful in supporting the data and information needs of this conceptual framework.

\section{Conclusions}

We describe a conceptual framework that considers the interrelationships between inherent characteristics, activities and behaviors, and stressors from the built, natural, and social environments in influencing children's health and well-being throughout their lifecourse (Figure 1). This framework can be used to guide decisions related to creating environments that promote healthy development for children and contribute to their well-being. To date, two publications using this conceptual framework have successfully explored the complexity of the interrelationships in chemical and non-chemical stressors that impact children's health and well-being.

Acknowledgements: The authors thank Betsy Smith (EPA), Jay Garland (EPA), Kim Gray (NIEHS), and Symma Finn (NIEHS) for constructive comments on the manuscript.

Competing Interests: The authors declare no competing interests.

Funding: The United States Environmental Protection Agency through its Office of Research and Development wholly funded the research described here. This research was partially supported by an appointment to the Internship/Research Participation Program at the U.S. Environmental Protection Agency, Office of Research and Development, National Exposure Research Laboratory, administered by the Oak Ridge Institute for Science and Education (ORISE) through an interagency agreement between the U.S. Department of Energy and EPA. It has been subjected to EPA administrative review and approved for publication. Mention of trade names or commercial products does not constitute endorsement or recommendation for use.

Statement of Human and Animal Rights: This article does not contain any studies with human participants or animals performed by any of the authors.

Informed Consent: Not applicable. 


\section{Reference}

1. U.S. EPA. Guidance on Selecting Age Groups for Monitoring and Assessing Childhood Exposures to Environmental Contaminants. (2005) Washington, DC: National Center for Environmental Assessment.

2. Cohen Hubal, E.A., de Wet, T., Du Toit, L., et al. Identifying important life stages for monitoring and assessing risks from exposures to environmental contaminants: results of a World Health Organization review. (2014) Regul Toxicol Pharmacol 69(1):113-124.

3. Cohen Hubal, E.A., Sheldon, L.S., Burke, J.M., et al. Children's exposure assessment: a review of factors influencing children's exposure, and the data available to characterize and assess that exposure. (2008) Environ Health Perspect 108(6): 475-486.

4. Juarez, P.D., Matthews-Juarez, P., Hood, D.B., et al. The public health exposome: a population-based, exposure science approach to health disparities research. (2014) Int J Environ Res Public Health 11(12):12866-12895

5. Seith, D., Isakson, E.A. Who Are America's Poor Children? Examining Health Disparities Among Children in the United States. (2011) New York, NY: Mailman School of Public Health, Columbia University.

6. Bedimo-Rung, A.L., Mowen, A.J., Cohen, D.A. The significance of parks to physical activity and public health: a conceptual model. (2005) Am J Prev Med 28(2 Suppl 2):159-168.

7. Taylor, W.C., Upchurch, S.L., Brosnan, C.A., et al. Features of the built environment related to physical activity friendliness and children's obesity and other risk factors. (2014) Public Health Nur 31(6): 545-555. 8. Esperat, M.C., Feng, D., Owen, D.C., et al. Transformation for health: a framework for health disparities research. (2005) Nur Outlook 53(3):113-120.

9. Briggs, D.J. A framework for integrated environmental health impact assessment of systemic risks. (2008) Environ Health 7: 61.

10. Halkitis, P.N., Kapadia, F., Ompad, D.C., et al. Moving toward a holistic conceptual framework for understanding healthy aging among gay men. (2015) J Homosexuality 62(5): 571-587.

11. Hancock, T. Beyond health care: from public policy to healthy public policy. (1985) Can J Public Health 76(Suppl 1): 9-11.

12. Krewski, D., Westphal, M., Andersen, M.E., et al. A framework for the next generation of risk science. (2014) Environ Health Perspect 122(8): 796-805.

13. Liu, H-Y., Bartonova, A., Pascal, M., et al. Approaches to integrated monitoring for environmental health impact assessment. (2012) Environ Health 11: 88.

14. Mistry, K.B., Minkovitz, C.S., Riley, A.W., et al. A new framework for childhood health promotion: the role of policies and programs in building capacity and foundations of early childhood health. (2012) Am J Public Health 102(9):1688-1696.

15. Morton, S.M.B., Atatoa Carr, P.E., Grant, C.C., et al. Growing Up in New Zealand: a longitudinal study of New Zealand children and their families. Vulnerability Report 1: Exploring the Definition of Vulnerability for Children in their First 1000 Days. (2014) Auckland, New Zealand: The University of Auckland.

16. Rehr, R., Miller, G., Foos, B. Children's environmental health indicators as tools to measure progress toward sustainability. (2015) Sustainability: Science, Practice, \& Policy 11(1).

17. Summers, J.K., Smith, L.M., Harwell, L.C., et al. An index of human well-being for the U.S.: a TRIO approach. (2014) Sustainability 6(6): 3915-3935.

18. Turner, B.L., Kasperson, R.E., Matson, P.A., et al. A framework for vulnerability analysis in sustainability science. (2003) Proc Natl Acad Sci USA 100(14): 8074-8079.

19. Vrijheid, M., Slama, R., Robinson, O., et al. The human early-life exposome (HELIX): project rationale and design. (2014) Environ Health Perspect 122(6): 535-544.

20. U.S. EPA. Framework for Cumulative Risk Assessment. (2003) Washington, DC: U.S. Environmental Protection Agency, EPA/630/P02/001F
21. U.S. EPA. A Conceptual Framework for U.S. EPA's National Exposure Research Laboratory. (2009) Washington, DC: U.S. Environmental Protection Agency, 2009 EPA/600/R-09/003.

22. WHO. Health In Sustainable Development Planning: The Role of Indicators; Chapter 7 - Framework for Linkages Between Health, Environment, and Development. (2002) Geneva, Switzerland: World Health Organizaiton.

23. Reading, C.L., Wien, F. Health Inequalities and Social Determinants of Aboriginal Peoples' Health. (2009) National Collaborating Centre for Aboriginal Health Prince George, BC.

24. Segal, D., Lin,Y-S., Ginsberg, G., et al. A conceptual framework for evaluating the interaction of a chemical and nonchemical stressor in human health risk assessments: a case study for lead and psychosocial stress. (2015) Hum Ecol Risk Assess 21:1840-1868.

25. Smith, L.M., Case, J.L., Smith, H.M., et al. Relating ecosystem services to domains of human well-being: foundation for a U.S. index. (2013) Ecol Indic 28: 79-90.

26. Bradshaw, J., Bloor, K., Huby, M., et al. Local Index of Child Well-Being: Summary Report. (2009) London, England.

27. Coker, R., Rushton, J., Mounier-Jack, S., et al. Towards a conceptual framework to support one-health research for policy on emerging zoonoses. (2011) Lancet Infect Dis 11(4): 326-331.

28. Land, K.C., Lamb, V.L., Mustillo, S.K. Child and youth well-being in the United States, 1975-1998: some findings from a new index. (2001) Soc Indic Res 56(3): 241-318.

29. UNICEF Office of Research. Child Well-Being in Rich Countries: A Comparative Overview. (2013) Florence: UNICEF Office of Research. 30. Adar, S.D., Huffnagle, G.B., Curtis, J.L. The respiratory microbiome: an underappreciated player in the human response to inhaled pollutants? (2016) Ann Epidemiol 26(5): 355-359.

31. Mai, V., Prosperi, M., Yaghjyan, L. Moving microbiota research toward establishing causal associations that represent viable targets for effective public health interventions. (2016) Ann Epidemiol 26(5): 306310.

32. Wang, M., Monaco, M.H., Donovan, S.M. Impact of early gut microbiota on immune and metabolic development and function. (2016) Semin Fetal Neonatal Med pii: S1744-165X(16)30004-X.

33. Feil, R., Fraga, M.F. Epigenetics and the environment: emerging patterns and implications. (2012) Nat Rev Genetics 13: 97-109.

34. Frieden, T.R. A framework for public health action: the health impact pyramid. (2010) Am J Public Health 100(4): 590-595.

35. Tulve, N.S., Jones, P.A., McCurdy, T., et al. A pilot study using an accelerometer to evaluate a caregiver's interpretation of an infant or toddler's activity level as recorded in a time activity diary. (2007) Res Q Exerc Sport 78(4): 375-383.

36. Sexton, K., Linder, S.H. Cumulative risk assessment for combined health effects from chemical and nonchemical stressors. (2011) Am J Public Health 101(Suppl 1): S81-S88.

37. Taylor, A..F, Kuo, F.E. Children with attention deficits concentrate better after walk in the park. (2009) J Attention Dis 12(5): 402-409.

38. Institute of Medicine and National Research Council. Child and Adolescent Health and Health Care Quality: Measuring What Matters. (2011) Washington, DC: The National Academies Press 320p.

39. Umberson, D., Crosnoe, R., Reczek, C. Social relationships and health behavior across life course. (2010) Annu Rev Sociol 36:139-157. 40. Lichtveld, K., Thomas, K., Tulve, N.S. Chemical and non-chemical stressors affecting childhood obesity: a state-of-the science review. (2016) J Exposure Sci Environ Epidemiol In Review.

41. U.S. EPA. Framework for Ecological Risk Assessment. (1992) Washington, DC: U.S. Government Printing Office.

42. Miranda, M.L., Edwards, S.E., Anthopolos, R., et al. The built environment and childhood obesity in Durham, NC. (2012) Clin Pediatr 51(8): 750-758.

43. Gray, S.C., Edwards, S.E., Schultz, B.D., et al. Assessing the impact of race, social factors and air pollution on birth outcomes: a population-based study. (2014) Environ Health 13: 4. 
44. Strominger, J., Anthopolos, R., Miranda, M.L. Implications of construction method and spatial scale on measures of the built environment. (2016) Int J Health Geographics 15: 15.

45. Shmool, J.L.C., Yonas, M.A., Newman, O.D., et al. Identifying perceived neighborhood stressors across diverse communities in New York City. (2015) Am J Community Psychol 56(1-2):145-155.

46. Clougherty, J.E., Levy, J.I., Kubzansky, L.D., et al. Synergistic effects of traffic-related air pollution and exposure to violence on urban asthma etiology. (2007) Environ Health Perspect 115(8):1140-1146.

47. Lewis, A.S., Sax, S.N., Wason, S.C., et al. Non-chemical stressors and cumulative risk assessment: an overview of current initiatives and potential air pollutant interactions. (2011) Int J Environ Res Public Health 8(6): 2020-2073.

48. U.S. EPA. Integrating Chemical and Non-Chemical Stressors in Cummulative Risk Assessment. (2011) U.S. EPA, Risk Assessment Forum.

49. Cox, L., Almeter, A.L., Saterson, K.A. Protecting our life support systems: an inventory of U.S. federal research on ecosystem services. (2013) Ecosyst Serv 5(2):163-169.

50. Cox, L., Hansen, V., Andrews, J., et al. Land Use: A Powerful Determinant of Sustainable \& Healthy Communities. (2013) Research Triangle Park, NC: U.S. Environmental Protection Agency.

51. Flanders, N., Baldauf, R., Yang, J., et al. Synthesis Paper on Sustainable Transportation. (2015) Research Triangle Park, NC: U.S. Environmental Protection Agency, 2015 EPA/600/R-14/278.

52. Zimmer, A., Ha, H-S., Andrews, J., et al. Buildings and Infrastucture from a Sustainability Perspective. (2014) Research Triangle Park, NC: U.S. Environmental Protection Agency, 2014.

53. CDC. Well-Being Concepts. (2013) Atlanta, GA: Centers for Disease Conrol and Prevention.

54. Gee, G.C., Payne-Sturges, D.C. Environmental health disparities: a framework integrating psychosocial and environmental concepts. (2004) Environ Health Perspect 112(17):1645-1653.

55. Mitchell, R., Popham, F. Effect of exposure to natural environment on health inequalities: an observational population study. (2008) The Lancet 372(9650): 1655-1660.

56. Thompson Coon, J., Boddy, K., Stein, K., et al. Does participating in physical activity in outdoor natural environments have a greater effect on physical and mental wellbeing than physical activity indoors? A systematic review. (2011) Environ Sci Technol 45(5):1761-1772.

57. Pretty, J., Angus, C., Bain, M., et al. Nature, Childhood, Health and Life Pathways. (2009) Cholchester, UK: University of Essex.

58. Thompson, C.W., Roe, J., Aspinall, P., et al. More green space is linked to less stress in deprived communities: evidence from salivary cortisol patterns. (2012) Landsc Urban Plan 105(3): 221-229.

59. Wood, B.K., Ferro, J.B., Umbreit, J., et al. Addressing the challenging behavior of young children through systematic function-based intervention. (2010) Topics Early Child Spec Educ 30(4): 221-232.

60. Baumgardner, D., Varela, S., Escobedo, F.J., et al. The role of a peri-urban forest on air quality improvement in the Mexico City megalopolis. (2012) Environ Pollut 163:174-183.

61. Jackson, L.E. The relationship of urban design to human health and condition. (2003) Landsc Urban Plan 64(4):191-200.

62. Nowak, D.J., Crane, D.E., Stevens, J.C. Air pollution removal by urban trees and shrubs in the United States. (2006) Urban For Urban Greening 4(3-4):115-123.
63. Ayotte, J.D., Nolan, B.T., Gronberg, J.A. Predicting arsenic in drinking water wells of the Central Valley, California. (2016) Environ Sci Technol 50(14): 7555-7563.

64. Ayers, J.C., Goodbred, S., George, G., et al. Sources of salinity and arsenic in groundwater in southwest Bangladesh. (2016) Geochem Trans 17: 4.

65. Komorowicz, I., Baralkiewicz, D. Determination of total arsenic and arsenic species in drinking water, surface water, wastewater, and snow from Wielkopolska, Kujawy-Pomerania, and Lower Silesia provinces, Poland. (2016) Environ Monit Assess 188(9): 504.

66. Kumar, M., Ramanathan, A., Rahman, M.M., et al. Concentrations of inorganic arsenic in groundwater, agricultural soils and subsurface sediments from the middle Gangetic plain of Bihar, India. (2016) Science Total Environ 573:1103-1114.

67. Bondu, R., Cloutier, V., Rosa, E., et al. Mobility and speciation of geogenic arsenic in bedrock groundwater from the Canadian Shield in western Quebec, Canada. (2016) Sci Total Environ 574: 509-519.

68. Tzortzis, M., Svoukis, E., Tsertos, H. A comprehensive study of natural gamma radioactivity levels and associated dose rates from surface soils in Cyprus. (2004) Radiat Prot Dosimetr 109(3): 217-224.

69. Probst, J.C., Barker, J.C., Enders, A., et al. Current state of child health in rural America: How context shapes children's health. (2016) J Rural Health.

70. National Research Council and Institute of Medicine. Children's Health, The Nation's Wealth: Assessing and Improving Child Health. (2004) Committee on Evaluation of Children's Health, editor. Washington, DC: The National Academies Press 336 p.

71. U.S. EPA. America's Children and the Environment. (2013) Washington, DC: 2013 EPA 240-R-13-001.

72. Chase-Lansdale, P.L., Moffitt, R.A., Lohman, B.J., et al. Mothers' transitions from welfare to work and the well-being of preschoolers and adolescents. (2003) Science 299(5612): 1548-1552.

73. U.S. EPA. Sustainable and Healthy Communities Strategic Research Action Plan. (2012) U.S. Environmental Protection Agency.

74. Friedman, D.J., Starfield, B. Models of population health: their value for U.S. public health practice, policy, and research. (2003) Am J Public Health 93(3): 366-369.

75. Adler, N.E., Rehkopf, D.H. U.S. disparities in health: descriptions, causes, and mechanisms. (2008) Annu Rev Public Health 29: 235-252. 76. Betts, K.S. Characterizing exposomes: tools for measuring personal environmental exposures. (2012) Environ Health Perspect 120(4): A158-A163.

77. Gustafsson, P.E., San Sebastian, M., Janlert, U., et al. Life-course accumulation of neighborhood disadvantage and allostatic load: empirical integration of three social determinants of health frameworks. (2014) Am J Public Health 104(5): 904-910.

78. Yee, S.H., Bradley, P., Fisher, W.S., et al. Integrating human health and environmental health into the DPSIR framework: a tool to identify research opportunities for sustainable and healthy communities. (2012) EcoHealth 9(4): 411-426.

79. Russ, S.A., Larson, K., Tullis, E., et al. A lifecourse approach to health development: implications for the maternal and child health research agenda. (2014) Matern Child Health J 18(2): 497-510.

80. Ruiz, J.D.C., Quackenboss, J.J., Tulve, N.S. Contributions of a child's built, natural, and social environments to their general cognitive ability: a systematic scoping review. (2016) Plos One 11(2): e0147741.
Ommega Online Publishers

Journal Title: Journal of Environment and Health Science (JEHS)

Journal Short Name: J Environ Health Sci
Journal ISSN: 2378-6841

E-mail: environmentalscience@ommegaonline.org

Website: www.ommegaonline.org 